\title{
Aims and structure of the study
}

The basic aim of this study is to provide a detailed formal and functional description and analysis of the clause types that are expressed in the Old Irish verbal complex. In particular, this study addresses three general questions:

(i) What are the Old Irish clause types distinguished in the verbal complex and what are the formal means expressing them?

(ii) How are Old Irish clause types formally and functionally related to each other?

(iii) Which other linguistic structures and domains are relevant for or interact in some significant manner with clause typing in Old Irish?

The morphological expression of clause typing in Old Irish reveals a number of functional associations among the clause types under inspection, but also between clause typing in general and other categories and syntactic structures. As a way of providing a framework for the answer to (iii) above, clause typing will be considered in the analysis of:

(1) a. Subordination,

b. Pragmatically marked structures such as left-dislocation and cleft-sentence,

c. Predicate types,

d. Pronominal arguments.

One of the most significant contributions of this monograph for the general study of clause typing is the illustration of the specific interaction of this category with the phenomena listed in (1). This study does not follow any particular school of linguistic thought, although the general orientation and the basic analytic tools considered come from the typological and functional literature.

The book is structured in three main parts. Part I (Chapters 1 to 3) describes the linguistic evidence on which the study is based and provides the morphological and syntactic descriptive issues that are necessary for a proper consideration of clause typing in Old Irish. Part II (Chapters 4 to 7 ) analyzes in turn the Old Irish clause types. Part III (Chapters 8 to 11) is devoted to the paradigmatic organization of the clause types described in the previous part, and includes a detailed study of two Old Irish verbal paradigms, those corresponding to the present in- 
dicative of the copula and of the substantive verb; as a complement to the previous chapters, it also devotes a chapter to the effect and interaction of clause typing with pronominal markers, both stressed and unstressed.

Chapter 1 has two main aims. On the one hand, it introduces the specific features that determine the linguistic evidence on which the present study is based. Special attention is paid to the so-called contemporaneous Old Irish texts, which involve a rather spontaneous linguistic production with a considerable degree of variation. On the other hand, this chapter introduces the notion of clause typing as a grammatical category.

Chapter 2 offers a comprehensive description of the formal aspects of the Old Irish verbal complex. The chapter discusses at length the consideration of this structure as a grammatical or morphosyntactic word, and establishes a theoretical template of six slots as well as their combinatorial restrictions. This description gives quite a systematic account of the elements appearing before and after the verbal stem, with the exception of the inflectional endings, which are left for Part II.

Chapter 3 analyzes and discusses the syntactic structures in which the Old Irish verbal complex appears in a position other than the unmarked V1 position. On the one hand, this chapter describes the cleft-sentence and left-dislocation; on the other, it deals with a group of alternative or irregular structures such as Bergin's Law and tmesis, which are restricted to literary texts.

The four chapters in Part II (Chapters 4 to 7) offer a formal and functional analysis of the six clause types distinguished in the Old Irish verbal complex, namely, the declarative, relative, content (or wh-) interrogative, polar interrogative, responsive and imperative clause types.

Chapter 4 describes the declarative and relative clause types in Old Irish verbs that have no (meaningful) conjunct particle, i.e. verbal forms that consist of the lexical basis, whether a simple verb or a lexical compound. This means discussing morphological markers of three types, basically: (i) the so-called absolute and conjunct endings, (ii) relative mutations and (iii) affixal pronouns. The pronominal references of the Old Irish verbal complex, those expressed as both inflectional endings and pronominal affixes, play a very important role in the distinction between declarative and relative clause types.

Chapter 5 poses the question as to how subordination is expressed in Old Irish, in view of the fundamental difference between declarative and relative clause type forms established in the previous chapter. A list of five formal strategies expressing subordination in Old Irish is introduced, which includes relative marking of various types, but also declarative clause type forms introduced by a subordinating conjunction. The main idea of the chapter is that the subordinate 
clauses which are 'less' subordinate are expressed by strategies that involve either relative nasalization or declarative clause type morphology.

Chapter 6 deals with the two strategies used to express content (or wh-) interrogative clause types in Old Irish. The most frequent one consists of a periphrastic expression in which the stressed wh-form (which may distinguish gender and number) is followed by a relative verb. A less frequent procedure involves the use of a less stressed wh-form that occupies the first slot in the template of the verbal complex, a slot that is reserved for pretonic elements.

Chapter 7 considers the three remaining clause types, i.e. polar interrogative, responsive and imperative clause types. These three clause types involve a relatively simple set of formal distinctions and, perhaps with the exception of the responsive clause type, their functional description is quite straightforward.

Part III is mainly devoted to the consideration of general aspects of the resulting paradigm of clause types in Old Irish, apart from the chapter of the conclusions.

Chapter 8 establishes the paradigm of clause types expressed in the Old Irish verbal complex. This paradigm is a sort of summary of the descriptive work of the previous parts, in the sense that it includes the six clause types considered in both their positive and negative forms as well as the possibility of including a pronominal reference.

Chapter 9 offers a detailed description of the Old Irish copula and substantive verb as carriers of two main types of non-verbal predication, namely, attributive and locational non-verbal predicates respectively. Special attention is paid herein to the paradigm of clause types in the present indicative of those two verbs, which display a very remarkable formal variability that includes suppletion determined by clause type distinctions. This chapter classifies and discusses the forms of those two verbal paradigms attested in the Old Irish contemporaneous texts and attempts to give a diachronic explanation for the alluded suppletive forms.

Chapter 10 describes and tries to give a diachronic explanation of some uses of personal pronouns in both their tonic and unstressed (affixal) variants that are somehow related to clause type distinctions. On the one hand, the use of the tonic pronouns that constitute an essential element in the expression of the third main type of non-verbal predication, i.e. the referential type, is considered. On the other, the affixal pronouns included in the Old Irish verbal complex sometimes lose their basic referential use and secondarily serve to mark some aspect related to clause typing.

Chapter 11 summarizes the main results of the study. 
